\title{
The effects of Gyrotonic expansion system exercise and trunk stability exercise on muscle activity and lumbar stability for the subjects with chronic low back pain
}

\author{
Hye-Ran Seo, Tae-Ho Kim* \\ Department of Physical Therapy, College of Rehabilitation Science, Daegu University, Gyeongsan, Korea
}

The Gyrotonic expansion system comprises three-dimensional (3D) spinal motion that not only improves functional spinal motion but also increases muscular strength and flexibility around the spine. This study aimed to demonstrate the clinical effect of Gyrotonic exercise on patients with chronic low back pain by comparing between Gyrotonic and trunk stability exercises. This study included 26 subjects with chronic low back pain patients and who were randomly assigned to the Gyrotonic exercise group or trunk stability exercise group. Each group performed their exercises 3 times a week for 4 weeks. All subjects were measured before and after the exercise for muscles activity of the erector spinae $(E S)$, rectus abdominis $(\mathrm{RA})$, external oblique (EO), and internal oblique (IO) using surface electromyography. Lumbar stability was measured using a 3D spine tester, and functional disability was measured using the Korean Oswestry disability index. In the Gyrotonic exercise group, ES and EO muscle activity significantly increased $(P<0.05)$. In the trunk stability exercise group, ES, EO, and RA muscle activity significantly increased $(P<0.05)$. No differences in muscle activity were found between the groups. Both groups showed significant improvements in lumbar stability and functional disability but no significant differences were noted between the groups. Gyrotonic exercise and trunk stability exercise are encouraged owing to their positive effects on muscle activity, lumbar stability, and functional ability in patients with chronic low back pain. We suggest that Gyrotonic exercise is one of the effective exercise for mitigating chronic low back pain caused by spinal instability.

Keywords: Gyrotonic expansion exercise, Chronic low back pain, Trunk stability, Electromyography, Lumbar stability

\section{INTRODUCTION}

Back pain refers to pain around the lumbar vertebrae in human body. O'sullivan et al. (2003) reported that as opposed to normal individuals, patients with chronic low back pain were more likely to experience instability of the spine owing to imbalanced and weak muscles around the vertebrae. Panjabi (2003) found that muscles around the vertebrae were needed to help maintain the correct alignment of the lumbar spine and pelvis to prevent and reduce low back pain, and Richardson and Jull (1995) suggested that trunk stability was established as a result of improvements in muscle functions around the vertebrae.

Trunk stability exercise is one of the most effective exercise

types that has been used not only for patients with low back pain but also in various fields as an intervention to improve posture balance and muscle strength around the vertebrae (Barr et al., 2005). The purpose of trunk stability exercise is to directly provide stability to the lumbar vertebrae when muscles of the external oblique (EO), internal oblique (IO), transverse abdominis, and lumbar multifidus are used to stand straight (Barker et al., 2004; Bergmark, 1989; Moseley et al., 2002; Panjabi, 2003).

The exercise performed using Gyrotonic expansion system is one of the intervention methods for the spine. It uses three-dimensional (3D) movements and a special equipment to not only strengthen the spine but also develop the spine evenly. The name is derived from the combination of "Gyro" (a circle) and "tonic" (to

${ }^{*}$ Corresponding author: Tae-Ho Kim (D) https://orcid.org/0000-0001-7939-2139 Department of Physical Therapy, College of Rehabilitation Science, Daegu University, 201 Daegudae-ro, Jillyang-eup, Gyeongsan 38453, Korea E-mail: ptkimth@daegu.ac.kr

Received: October 17, 2018 / Accepted: December 31, 2018
This is an Open Access article distributed under the terms of the Creative Commons Attribution Non-Commercial License (http://creativecommons.org/licenses/by-nc/4.0/) which permits unrestricted non-commercial use, distribution, and reproduction in any medium, provided the original work is properly cited. 
strengthen). The core principle underlying Gyrotonic exercise is a movement that creates circles, spirals, and undulation curves, these natural movements improve muscle strength and flexibility along with breathing and collaborative muscle contraction that help stretch each area of the body (Campbell and Miles, 2006). One study has found proof of the effects of step length, stride length, step sidth, and stride speed in the gait pattern in patients with chronic low back pain (Seo and Park, 2016). Although a number of studies have been conducted on patients with chronic low back pain, studies on the specific effects of Gyrotonic exercise on muscle activities and lumbar stability of these patients are still relatively insufficient.

Therefore, the purpose of this study is to demonstrate the clinical effect of Gyrotonic exercise on chronic low back pain patients by comparing Gyrotonic exercise and trunk stability exercise. We suggest that Gyrotonic exercise is an effective exercise of chronic low back pain.

\section{MATERIALS AND METHODS}

\section{Subjects}

The subjects in this study were 26 patients (mean age, 22.62 \pm 1.58 years; mean height, $166.62 \pm 8.24 \mathrm{~cm}$; mean weight, $57.15 \pm$ $9.25 \mathrm{~kg}$ ) (Table 1). The detailed selection criteria were as follows: (a) patients who had been experiencing low back pain for 3 months or longer and were not under treatment for low back pain; (b) patients able to perform exercises despite having low back pain; (c) patients free of previous orthopedic or neurosurgical surgeries around the lumbar; (d) patients free of sensory abnormalities or muscle paralysis caused by neurological disorders; (e) patients not suffering from low back pain caused by systemic diseases such as cancer or pregnancy; and (f) patients free of difficulties in motor performance or mental disorders. In this study, subjects were randomly divided into Gyrotonic and trunk stability exercise groups. All subjects were fully informed about the purpose of study and methods used in this study, and they voluntarily signed the study

Table 1. General characteristics of subjects

\begin{tabular}{lcccc}
\hline Characteristic & $\begin{array}{c}\text { Gyrotonic } \\
\text { exercise }\end{array}$ & $\begin{array}{c}\text { Trunk stability } \\
\text { exercise }\end{array}$ & $t$ & $P$-value \\
\hline Gender, male:female & $6: 7$ & $5: 8$ & & \\
Age $(\mathrm{yr})$ & $22.31 \pm 1.60$ & $22.92 \pm 1.55$ & -0.19 & 0.851 \\
Height $(\mathrm{cm})$ & $166.31 \pm 7.84$ & $166.92 \pm 8.62$ & 0.68 & 0.505 \\
Weight $(\mathrm{kg})$ & $57.15 \pm 9.73$ & $57.13 \pm 8.76$ & 0.99 & 0.330 \\
\hline
\end{tabular}

Values are presented as number or mean \pm standard deviation. consent form. This study was approved by the Institutional Review Board of Daegu University (No: 1040621-201711-HR-030-002).

\section{Exercise program using Gyrotonic expansion system}

Gyrotonic exercise used the Pulley Tower Combination Unit ULTIMA (Gyrotonic Inc., New York, NY, USA). The Gyrotonic exercise program consisted of a warm-up session, main exercise, and a cool-down session. According to the rating of perceived exertion (PRE), warm-up exercise strength was set from PRE 9 (very light feeling) to 11 (slightly light feeling), the main exercise strength was set from PRE 13 (somewhat hard feeling) to 15 (hard feeling), and the cool-down exercise was set at PRE 9. Five movements of the lumbar spine were used during the warm-up session. Main exercise motions included four movements in the arch and curl series, eight in the hamstring series, one in the upper body series, and two in the abdominal series (for a total of 20 motions). Two movements were used during the cool-down session.

\section{Trunk stability exercise program}

Trunk stability exercise used mats and Swiss balls. The sizes and amount of air in the Swiss balls were adjusted according to the subject preference. According to the RPE criteria, the strength of the trunk stability exercises was set at RPE 9-11 for the warmup session; RPE 13-15, main exercise; and RPE 9, cool-down session. Simple stretching and deep breathing motions were used for the warm-up exercise. Main exercise motions included nine movements of mat-based trunk stability exercises and seven movements of Swiss ball trunk stability exercises (for a total of 16 different motions of ten repetitions each). Simple stretching and deep breathing were conducted for the cool-down exercise (Koumantakis et al., 2005; Marshall and Murphy, 2005)

\section{Muscle activities}

Surface electromyography (sEMG) 8-channel TeleMyo DTS (Noraxon Inc., Scottsdale, AZ, USA) was used to measure trunk muscle activity. We measured the activity of the erector spinae (ES), rectus abdominis (RA), EO, and IO, which stabilize the trunk. Electrodes were attached to each of the muscles after marking their places with a pen in accordance with previous studies (Cram, 2003; Imai et al., 2010). The EMG signal was processed for filtering and other signals by a personal computer, and the sampling rate of the EMG signal was set to 1,000 $\mathrm{Hz}$. The amplified waveform was composed of a $40-400 \mathrm{~Hz}$ bandpass filter, and a $60 \mathrm{~Hz}$ noise root mean square (RMS) was used to quantify the collected EMG signals (Ritvanen et al., 2007). This study nor- 
malized the effective mean values using the reference voluntary contraction (RVC) value. The reference posture of the RVC was a prone bridge using a ball. Each subject maintained this position for $5 \mathrm{sec}$ and then repeated the movement 3 times. For each subject, we used the mean values of the middle $3 \mathrm{sec}$. For muscle activity measurement, each subject sat on the ball and bent one leg up to the chest. Each subject maintained this position for $5 \mathrm{sec}$ and then repeated the movement 3 times. For each subject, we used the mean values of the middle $3 \mathrm{sec}$. The muscle activities were normalized to \% RVC as a percentage of the RMS of the measured posture relative to the RMS of the reference posture.

\section{Lumbar stability}

3D spine tester (3D Newton, Hanmed, Gimhae, Korea) was used to compare lumbar stability. The 3D Newton is a piece of equipment used for measuring the stability of the spine in 3D. We took measurements in the correct standing posture, with patients tilted at $30^{\circ}$ in eight directions (front, back, right, left, between front and right, between front and left, between back and right, between back and left). In the $30^{\circ}$ tilt position, we measured the maximum endurance time (in sec) of each subjects. If the subjects felt fatigued or experienced pain or if they wanted to stop undergoing the assessment, the measurement was halted immediately. The assessment was repeated 3 times and each patient took sufficient rest between the assessments. We used the mean value of the measured time in the study.

\section{Functional disability index}

The Korean Oswestry disability index (KODI) was used to compare the functional disability caused by chronic low back pain between the subject groups. The nine sections of KODI consist of questions regarding pain, personal care, lifting, walking, sitting, sleeping, social life, and travel (we excluded sex life because it participants generally tend to avoid answering related questions). Each item or section had a maximum score of 5 points beginning with 0 points (on a 6-point scale), and the total score is 45 points. Scores for each of the 9 items were divided by the total score and converted into a percentage (measurement score/overall score $\times 100$ ). Low scores indicate low quality of life associated with back pain (Kim et al., 2005).

\section{Statistical analyses}

The statistical processing and analysis used IBM SPSS Statistics ver. 23.0 (IBM Co., Armonk, NY, USA). Means and standard de

Table 2. The comparison of electromyogarphy in each of the exercise at pre post (unit: \%RVC)

\begin{tabular}{|c|c|c|c|c|c|}
\hline Variable & Pre & Post & Difference value & $t$ & $P$-value \\
\hline \multicolumn{6}{|l|}{ Erector spinae } \\
\hline Gyrotonic exercise & $46.05 \pm 32.99$ & $75.65 \pm 33.65$ & $29.61 \pm 38.67$ & 2.76 & $0.017^{*}$ \\
\hline Trunk stability exercise & $55.31 \pm 47.95$ & $86.13 \pm 72.12$ & $30.82 \pm 36.37$ & 3.05 & $0.010^{*}$ \\
\hline$t$ & -0.570 & - & 0.780 & & \\
\hline$P$-value & 0.571 & - & 0.935 & & \\
\hline \multicolumn{6}{|l|}{ Rectus abdominis } \\
\hline Gyrotonic exercise & $130.91 \pm 68.77$ & $139.20 \pm 87.13$ & $8.33 \pm 20.68$ & 1.45 & 0.172 \\
\hline Trunk stability exercise & $136.26 \pm 34.58$ & $157.67 \pm 64.02$ & $21.41 \pm 35.26$ & 2.19 & $0.049^{*}$ \\
\hline$t$ & -0.250 & - & 0.382 & & \\
\hline$P$-value & 0.804 & - & 0.260 & & \\
\hline \multicolumn{6}{|l|}{ External oblique } \\
\hline Gyrotonic exercise & $84.41 \pm 17.91$ & $102.65 \pm 26.00$ & $18.23 \pm 18.13$ & 3.63 & $0.003^{*}$ \\
\hline Trunk stability exercise & $92.27 \pm 25.67$ & $107.71 \pm 27.88$ & $15.43 \pm 20.95$ & 2.65 & $0.021^{*}$ \\
\hline$t$ & -0.910 & - & -0.370 & & \\
\hline$P$-value & 0.374 & - & 0.718 & & \\
\hline \multicolumn{6}{|l|}{ Internal oblique } \\
\hline Gyrotonic exercise & $144.94 \pm 72.96$ & $156.15 \pm 98.40$ & $1.22 \pm 37.25$ & 1.09 & 0.299 \\
\hline Trunk stability exercise & $142.60 \pm 46.45$ & $160.13 \pm 56.03$ & $17.53 \pm 20.24$ & 2.09 & 0.059 \\
\hline$t$ & 0.100 & - & 0.480 & & \\
\hline$P$-value & 0.923 & - & 0.639 & & \\
\hline
\end{tabular}

Values are presented as mean \pm standard deviation. ${ }^{*} P<0.05$. 
Table 3. The comparison of lumbar stability in each of the exercise at pre and post (unit: sec)

\begin{tabular}{lccccc}
\hline Group & Pre & Post & $\begin{array}{c}\text { Difference } \\
\text { value }\end{array}$ & $Z$ & $P$-value \\
\hline Gyrotonic exercise & $17.08 \pm 5.27$ & $20.83 \pm 4.53$ & $3.75 \pm 4.44$ & -3.04 & $0.010^{*}$ \\
Trunk stability exercise & $15.57 \pm 8.06$ & $23.41 \pm 8.75$ & $7.85 \pm 7.79$ & -3.63 & $0.003^{*}$ \\
$t$ & 0.570 & - & -1.650 & & \\
$P$-value & 0.576 & - & 0.116 & & \\
\hline
\end{tabular}

Values are presented as mean \pm standard deviation. ${ }^{*} P<0.05$.

viations of the general characteristics and variables of the subjects were calculated and the Shapiro-Wilks test for normality was conducted. The difference in functional disability before and after each group exercise was Mann-Whitney $U$-test. The difference between the exercise groups was Wilcoxon test. The difference in muscle activity and lumbar stability before and after each group exercise was paired $t$-test. The difference between the exercise groups was independent $t$-test. The statistical significance level was set at a $P$-value of 0.05 .

\section{RESULTS}

The Gyrotonic exercise group showed significantly increased activity of $\mathrm{ES}$ and $\mathrm{EO}$ muscles before and after the exercise $(P<$ 0.05 ) (Table 2). The trunk stability exercise group demonstrated a significant increase in activity of ES, RA, and EO muscles before and after the exercise $(P<0.05)$ (Table 2). Both groups showed significant improvements in lumbar stability (Table 3 ) and KODI $(P<0.05)$ (Table 4). No significant differences with regard to muscle activity, lumbar stability, or KODI were noted between the 2 groups $(P<0.05)$.

\section{DISCUSSION}

The ES, RA, and EO, which are superficial lumbar muscles that play a role in supporting and stabilizing the lumbar vertebrae, are involved in spinal stability through concentric contraction during rapid movements or application of loads to the spine (McGill et al., 2003). The EO also helps to maintain the normal vertebral alignment by preventing rotation of the lumbar (Souza et al., 2001). Gyrotonic exercises are based on the movement of the front, back, side, spiral, and circular movements of the spine. Among these movements, the arch and curl motion, in which the subject draws a big circle using the spine, has been considered to create a connection between the ES and EO muscles. The arch and
Table 4. The comparison of functional disability index in each of the exercise at pre and post (unit: score)

\begin{tabular}{lccccc}
\hline Group & Pre & Post & $\begin{array}{c}\text { Difference } \\
\text { value }\end{array}$ & Z & $P$-value \\
\hline Gyrotonic exercise & $14.87 \pm 6.75$ & $11.36 \pm 5.74$ & $-0.35 \pm 2.02$ & -3.075 & $0.002^{*}$ \\
Trunk stability exercise & $12.81 \pm 5.89$ & $7.77 \pm 5.59$ & $-5.04 \pm 5.45$ & -3.203 & $0.001^{*}$ \\
$U$ & 70.500 & - & 84 & & \\
P-value & 0.479 & - & 1 & & \\
\hline
\end{tabular}

Values are presented as mean \pm standard deviation

${ }^{*} P<0.05$.

curl motion is used in all units that employ a handle and pulley, an upper body series, and an abdominal series. Trunk stability exercises also help to maintain a neutral posture of the spine. Thus, both Gyrotonic and trunk stability exercises are thought to increase activity in muscles that play a role in supporting and stabilizing the lumbar vertebrae.

Both the Gyrotonic exercise and trunk stability exercise groups showed significant improvement with regard to functional disability before and after the exercises, and no significant difference were revealed between them. Hides et al. (2001) and Stuge et al. (2004) reported that muscle imbalance, which was the cause of back pain, improved with exercise and that muscles acted like corsets to reduce back pain and improve functionality. Therefore, Gyrotonic exercise and trunk stability exercise have significant effects on functional ability.

Stability means the maintenance of a certain state even in the presence of external stimulus. Increased changes in lumbar stability indicate that the spine can maintain a neutral posture despite stimulation around the lumbar (Granata et al., 2005). In this study, the results revealed an increased lumbar muscle activity and an increased maintenance time of passive tilt to maintain lumbar stability. This suggests that both Gyrotonic exercise and trunk stability exercise are effective in improving lumbar stability.

The motions in Gyrotonic exercise are based on movements in the front, back, right, and left directions as well as in the form of spiral (basic movements of the spine). These are similar to functional motions in daily living. Trunk stability exercise involves mobilizing stabilization muscles involuntarily, which are otherwise mobilized late during functional motions. Thus, it is an effective exercise for improving functional motions. Rasmussen-Barr et al. (2003) reported that the intensity of low back pain in patients who performed a stabilization exercise was lesser than that in patients who only performed spinal manipulation. Similarly, this study found that both of Gyrotonic exercise and trunk stability exercise improved spinal stability, muscle activity, lum- 
bar stability, and functional ability, and no significant differences were found between the two exercise groups.

The present study had several limitations. It is difficult to generalize its results due to the small number of subjects. In addition, this study had a relatively short period of intervention of 4 weeks. Although the 4-week period was set up based on a previous study that achieved a significant reduction in low back pain, most related studies applied 6-12 weeks to verify the change. Thus, a 4-week study period may not be sufficient to expect a permanent change. For future studies, more subjects and longer experiment periods will be applied to determine the effects of the exercises. This study suggests that Gyrotonic exercise, as one of the many spinal stability exercises, can also be useful for improving spinal stability in patients with chronic low back pain.

\section{CONFLICT OF INTEREST}

No potential conflict of interest relevant to this article was reported.

\section{REFERENCES}

Barker KL, Shamley DR, Jackson D. Changes in the cross-sectional area of multifidus and psoas in patients with unilateral back pain: the relationship to pain and disability. Spine (Phila Pa 1976) 2004;29:E515-519.

Barr KP, Griggs M, Cadby T. Lumbar stabilization: core concepts and current literature, Part 1. Am J Phys Med Rehabil 2005;84:473-480.

Bergmark A. Stability of the lumbar spine. A study in mechanical engineering. Acta Orthop Scand Suppl 1989;230:1-54.

Campbell J, Miles W. Analyzing the Gyrotonic ${ }^{\circledR}$ arch and curl. J Bodyw Mov Ther 2006;10:147-153.

Cram JR. The history of surface electromyography. Appl Psychophysiol Biofeedback 2003;28:81-91.

Granata KP, Lee PE, Franklin TC. Co-contraction recruitment and spinal load during isometric trunk flexion and extension. Clin Biomech (Bristol, Avon) 2005;20:1029-1037.

Hides JA, Jull GA, Richardson CA. Long-term effects of specific stabilizing exercises for first-episode low back pain. Spine (Phila Pa 1976) 2001;26:E243-248.

Imai A, Kaneoka K, Okubo Y, Shiina I, Tatsumura M, Izumi S, Shiraki H. Trunk muscle activity during lumbar stabilization exercises on both a stable and unstable surface. J Orthop Sports Phys Ther 2010;40:369375 .

Kim DY, Lee SH, Lee HY, Lee HJ, Chang SB, Chung SK, Kim HJ. Validation of the Korean version of the oswestry disability index. Spine (Phila Pa 1976) 2005;30:E123-127.

Koumantakis GA, Watson PJ, Oldham JA. Trunk muscle stabilization training plus general exercise versus general exercise only: randomized controlled trial of patients with recurrent low back pain. Phys Ther 2005;85:209-225.

Marshall PW, Murphy BA. Core stability exercises on and off a Swiss ball. Arch Phys Med Rehabil 2005;86:242-249.

McGill SM, Grenier S, Kavcic N, Cholewicki J. Coordination of muscle activity to assure stability of the lumbar spine. J Electromyogr Kinesiol 2003;13:353-359.

Moseley GL, Hodges PW, Gandevia SC. Deep and superficial fibers of the lumbar multifidus muscle are differentially active during voluntary arm movements. Spine (Phila Pa 1976) 2002;27:E29-36.

O'Sullivan PB, Burnett A, Floyd AN, Gadsdon K, Logiudice J, Miller D, Quirke H. Lumbar repositioning deficit in a specific low back pain population. Spine (Phila Pa 1976) 2003;28:1074-1079.

Panjabi MM. Clinical spinal instability and low back pain. J Electromyogr Kinesiol 2003;13:371-379.

Rasmussen-Barr E, Nilsson-Wikmar L, Arvidsson I. Stabilizing training compared with manual treatment in sub-acute and chronic low-back pain. Man Ther 2003;8:233-241.

Richardson CA, Jull GA. Muscle control-pain control. What exercises would you prescribe? Man Ther 1995;1:2-10.

Ritvanen T, Zaproudina N, Nissen M, Leinonen V, Hänninen O. Dynamic surface electromyographic responses in chronic low back pain treated by traditional bone setting and conventional physical therapy. J Manipulative Physiol Ther 2007;30:31-37.

Seo KE, Park TJ. Effects of gyrokinesis exercise on the gait pattern of female patients with chronic low back pain. J Phys Ther Sci 2016;28:511514.

Souza GM, Baker LL, Powers CM. Electromyographic activity of selected trunk muscles during dynamic spine stabilization exercises. Arch Phys Med Rehabil 2001;82:1551-1557.

Stuge B, Laerum E, Kirkesola G, Vøllestad N. The efficacy of a treatment program focusing on specific stabilizing exercises for pelvic girdle pain after pregnancy: a randomized controlled trial. Spine (Phila Pa 1976) 2004;29:351-359. 